\title{
Extreme Extended Multi-wavelength Propagation due to Hot and Dry Air Flowing Over the Persian Gulf
}

\author{
Robert Marshall, Victor Wiss, Katherine Horgan, William Thornton, Edward Burgess \\ Electromagnetic and Sensor Systems Department \\ Naval Surface Warfare Center Dahlgren Laboratory \\ Dahlgren, Virginia, USA \\ robert.e.marshall@navy.mil
}

\begin{abstract}
Shallow surface radio frequency $(R F)$ trapping layers or ducts form in stable internal boundary layers (SIBL) when warm dry air flows offshore over colder and more humid sea surfaces. Depending on wind speed and land sea temperature difference, these surface ducts can exist for hundreds of kilometers offshore and trap radar energy in layers below 100m above sea level. This paper describes the performance of notional shore based $S, C$ and $X$ band radars during a SIBL event. The three dimensional (3D) verified refractivity field is modeled by the Coupled Ocean Atmosphere Mesoscale Prediction System $\left(C O A M P S^{\circledR}\right)$. The radar performance is modeled by the Advanced Refractive Effects Prediction System (AREPS).
\end{abstract}

\section{INTRODUCTION}

$\mathrm{RF}$ refraction is typically enhanced in thermally stable atmospheric layers over water where vertical thermodynamic mixing is inhibited. This lack of turbulently induced mixing allows for strong vertical gradients in absolute water vapor and temperature that leads to non-standard gradients in modified refractivity. The gradient in modified refractivity (M) is related to gradients in water vapor mixing ratio $(w)$ and potential temperature $(\theta)$ as given in (1). Depending on temperature and relative humidity, the water vapor term in (1) can be two to six times the potential temperature term

$$
d M / d z \cong 0.128+c_{1} d w / d z-c_{2} d \theta / d z
$$

Table 1 quantifies the categories of RF propagation in terms of the vertical gradient of modified refractivity. The surface ducting described in this paper is created when the vertical gradient of $\mathrm{M}$ is less than zero. The warm air flowing over the colder ocean produces a thermally stable surface layer characterized by a positive vertical gradient of $\theta$ that nudges the left side of (1) towards zero. The air flowing off the land, in this case, is less humid than the air at the sea surface resulting in a negative vertical gradient of $\mathrm{w}$ that forces the left side of (1) below zero [1,2].
TABLE I. PROPAGATION CATEGORIES

\begin{tabular}{|l|c|c|}
\hline $\begin{array}{l}\text { Behavior } \\
(\mathrm{dM} / \mathrm{dz}) \mathrm{m}^{-1}\end{array}$ & Range 1 & Range 2 \\
\hline Standard & \multicolumn{2}{|c|}{$=0.118$} \\
\hline Ducting & $<0.0$ & 0.079 \\
\hline $\begin{array}{l}\text { Super- } \\
\text { refractive }\end{array}$ & 0.0 & 0.157 \\
\hline Normal & 0.079 & $>0.157$ \\
\hline Sub-refractive & & \\
\hline
\end{tabular}

\section{THREE DIMENSIONAL REFRACTIVITY FIELD}

COAMPS $^{\circledR}$ [3] was employed to model vertical profiles of $\mathrm{w}, \theta$ and $\mathrm{M}$ in northwest flow from the northwestern end of the Persian Gulf to $600 \mathrm{~km}$ downwind at $1200 \mathrm{UTC}$ on May 14, 2009. The horizontal resolution of the profiles is $3 \mathrm{~km}$. 58 vertical levels were used in the model with 10 levels within the first $100 \mathrm{~m}$ in order to resolve the resulting shallow SIBL structure. Figure 1 displays the wind flags at $100 \mathrm{~m}$ above sea level (ASL). At this time, warm and less humid air flowed off the land over a colder and more humid sea surface. The red dashed line is $600 \mathrm{~km}$ long at 135 degrees true. The star indicates the position of the notional $\mathrm{S}, \mathrm{C}$ and $\mathrm{X}$ band radars modeled in this study. Along the 135 degree true line the NW flow is fairly consistent. But it can be seen that a towards coast flow associated with a sea breeze circulation develops near the south and north shores of the Persian Gulf. This will impact the azimuth dependent radar performance as will be shown in the following analysis. 


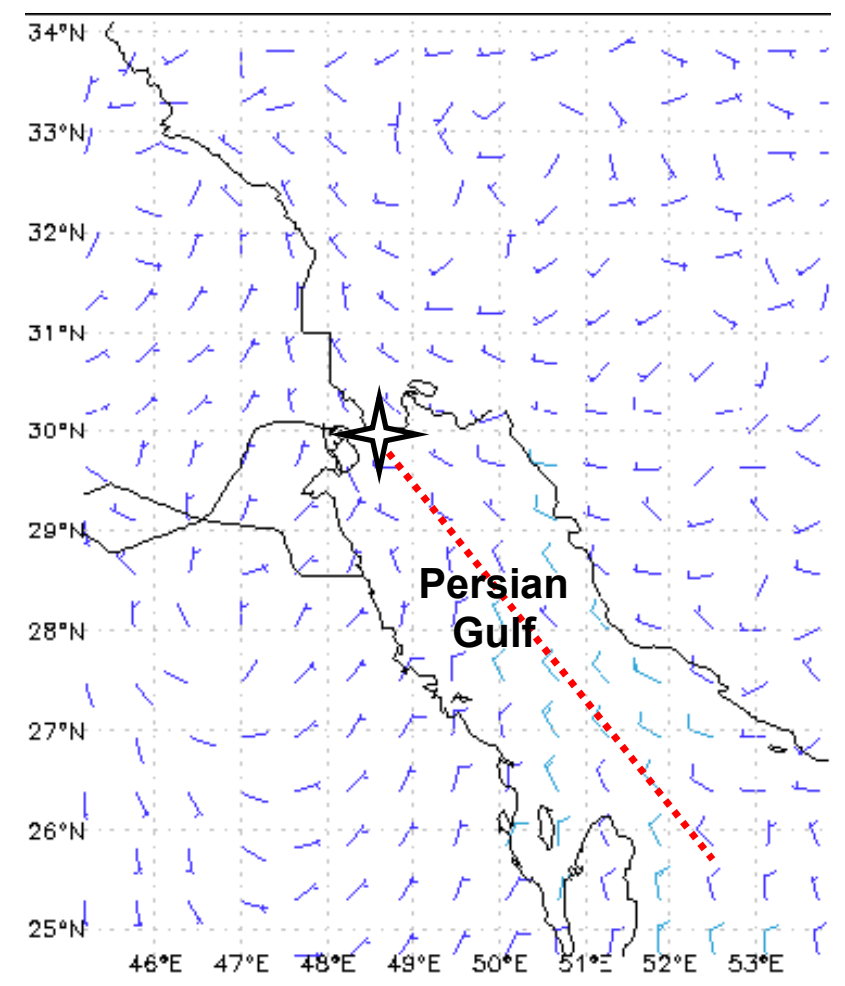

Figure 1. Wind flags $100 \mathrm{~m}$ ASL at $1200 \mathrm{UTC}$ on May 14,2009 . The dashed red line is $600 \mathrm{~km}$ long at $135 \mathrm{deg}$ true. Shore based S, C and X band radars are modeled and located at the star.

Figure 2 represents COAMPS $^{\circledR}$ modeled profiles of potential temperature along the red dashed line in figure 1 . At $0 \mathrm{~km}$ along the shoreline, potential temperature rapidly increases from the surface up to $25 \mathrm{~m}$ above sea level (ASL). The temperature of $300.5 \mathrm{~K}$ at $5 \mathrm{~m}$ ASL is representative of the sea surface temperature (SST) and the temperature of $304.5 \mathrm{~K}$ at $25 \mathrm{~m} \mathrm{ASL}$ is representative of the temperature of the air flowing offshore. From the shoreline out to $400 \mathrm{~km}$, it can be seen that the strength of the gradient in $\theta$ decreases and the height of the layer increases from 25 to $150 \mathrm{~m}$ ASL. But by $500 \mathrm{~km}$, the SIBL is lowered to $110 \mathrm{~m}$ ASL and the strength of the gradient in $\theta$ is increased.

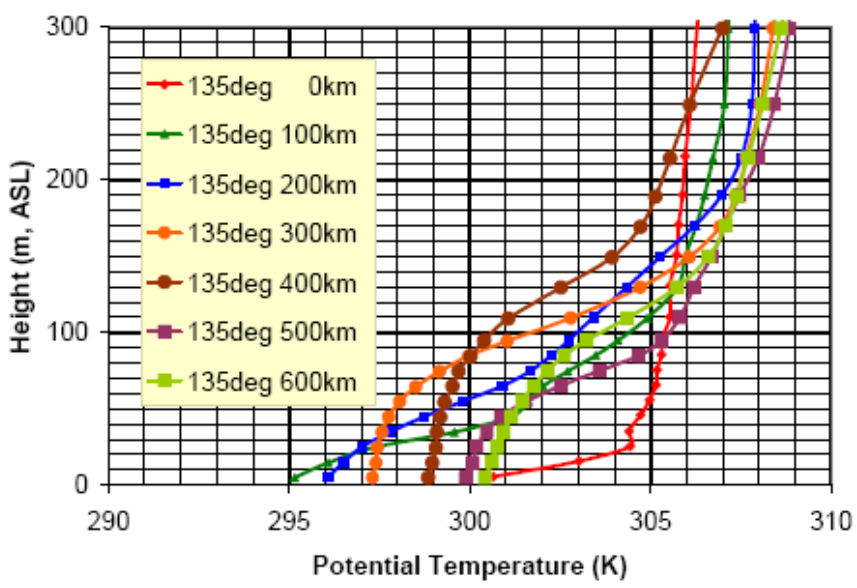

Figure 2. Vertical profiles of potential temperature along the 135 degree true line delineated in figure 1 at 1200UTC on May 14, 2009.
This is due to an increase in the air-sea temperature difference (ASTD) as will be shown in a following diagram. At $600 \mathrm{~km}$ from the shoreline, the SIBL height has increased to $130 \mathrm{~m}$ ASL.

The profiles for $\mathrm{w}$ along the same path are shown in figure 3. As with $\theta$, the layers increase in height out to $400 \mathrm{~km}$ offshore, decrease by $500 \mathrm{~km}$ and increase between 500 and $600 \mathrm{~km}$ offshore. The vertical gradients in $\theta$ and $\mathrm{w}$ shown in figures 2 and 3 create strong negative vertical gradients in $\mathrm{M}$ as predicted by (1). These are shown in figure 4 as surface ducts that grow from $25 \mathrm{~m}$ ASL near the shore to $170 \mathrm{~m}$ ASL at $400 \mathrm{~km}$ offshore. Due to an increase in the ASTD, the duct height decreases to $110 \mathrm{~m}$ ASL at $500 \mathrm{~km}$ offshore and increases to $160 \mathrm{~m}$ ASL at $600 \mathrm{~km}$.

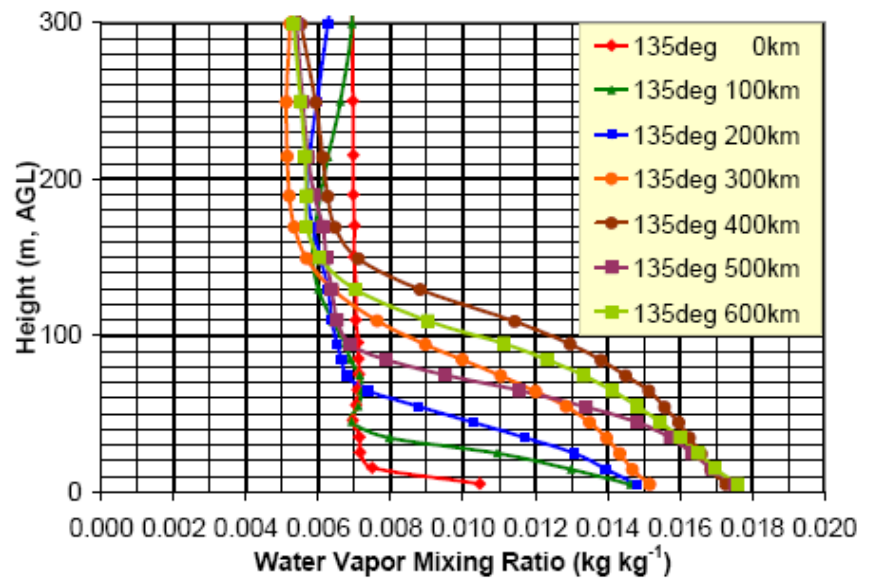

Figure 3. Vertical profiles of water vapor mixing ratio along the 135 degree true line delineated in figure 1 at 1200UTC on May 14, 2009.

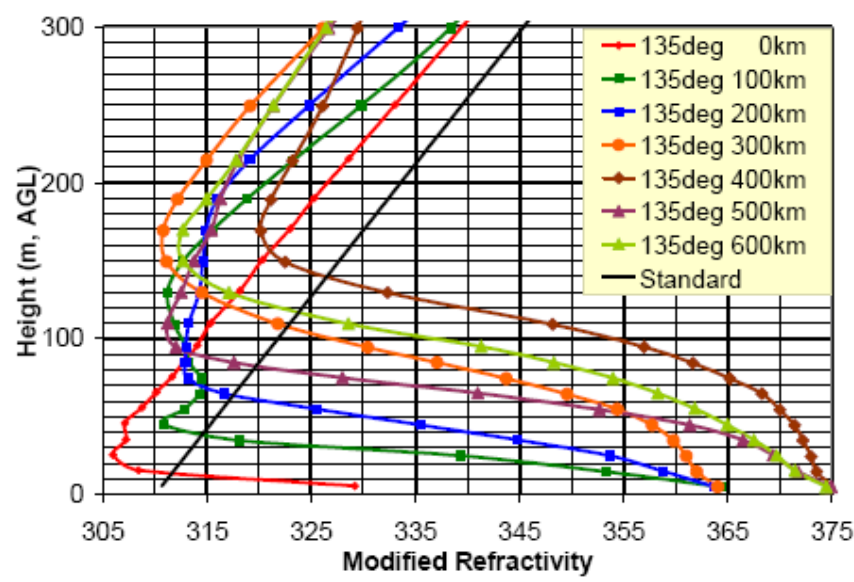

Figure 4. Vertical profiles of modified refractivity along the 135 degree true line delineated in figure 1 at 1200UTC on May 14, 2009.

The ASTD along the 135 degree azimuth is displayed in figure 5 . 


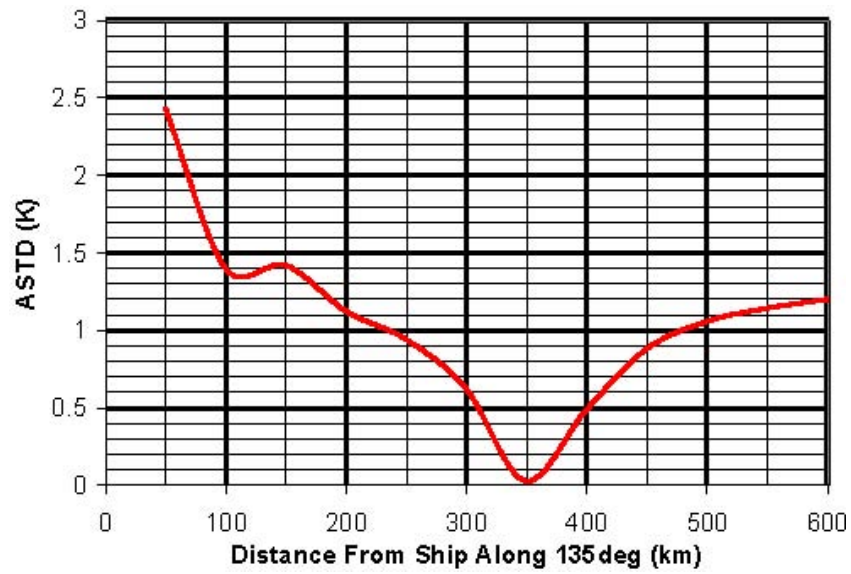

Figure 5. ASTD along the 135 degree true line delineated in figure 1 at 1200UTC on May 14, 2009.

\section{RADAR MODELING}

Notional S, C and X-band radars were modeled with the Advanced Refractive Effects Prediction System (AREPS), [4]. The radars were designed to have equal probability of detecting a notional target in free space thereby allowing wavelength dependent environment effects to be observed. AREPS employed the COAMPS ${ }^{\circledR}$ refractivity field and the radar design parameters to calculate propagation factor. Figure 6 displays the S-band propagation factor along the 135 degree azimuth indicated by the red dashed line in figure 1 . The positive red propagation factor indicates that the SIBL or trapping layer increases in height in the downwind direction. Notice that at approximately $350 \mathrm{~km}$ downwind, the trapping layer begins to flatten and then decrease in height in response to increase in air-sea temperature difference.

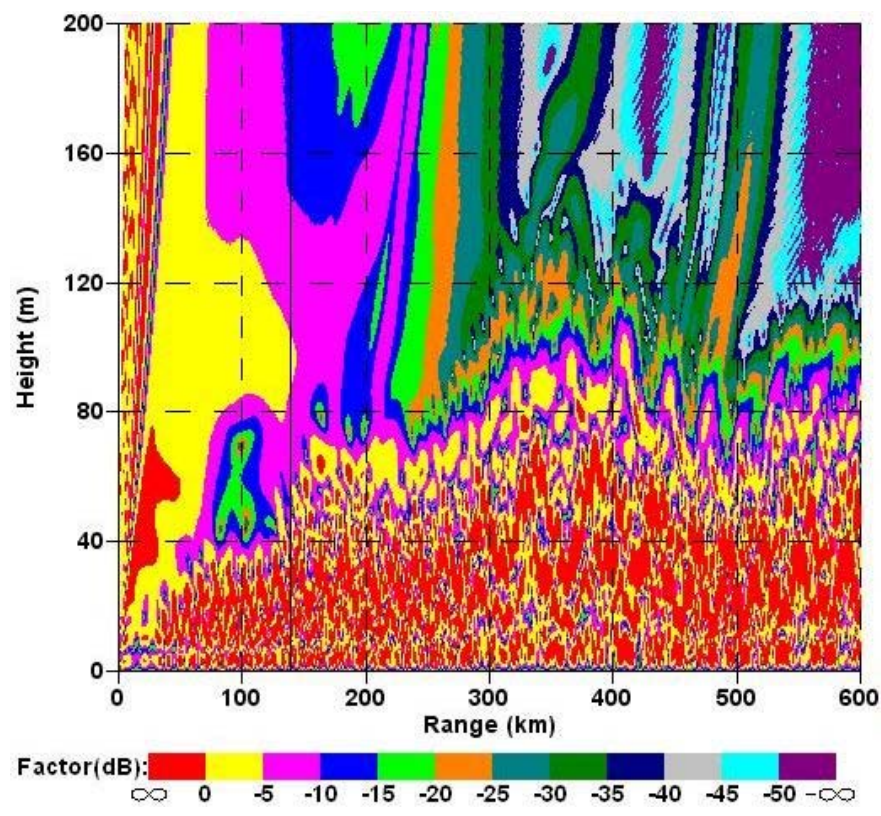

Figure 6. S band propagation factor along the 135 degree azimuth indicated by the dashed red line in figure 1 at 1200UTC on May 14, 2009.
After about $500 \mathrm{~km}$, the trapping layer begins to increase in height. Also noticeable is a broadened area of 0 to $-5 \mathrm{~dB}$ propagation factor at closer ranges up to $200 \mathrm{~m}$ ASL.

Radar detection performance is shown in figure 7 for a notional target located $10 \mathrm{~m}$ ASL. The $\mathrm{S}$ band radar is located at the shoreline and is scanned between 123 and 153 degrees. The white areas indicate detection of the notional target. AREPS employs the surface wind data from each COAMPS ${ }^{\circledR}$ grid point for a clutter model to predict clutter to noise ratio as part of the probability of detection calculation.

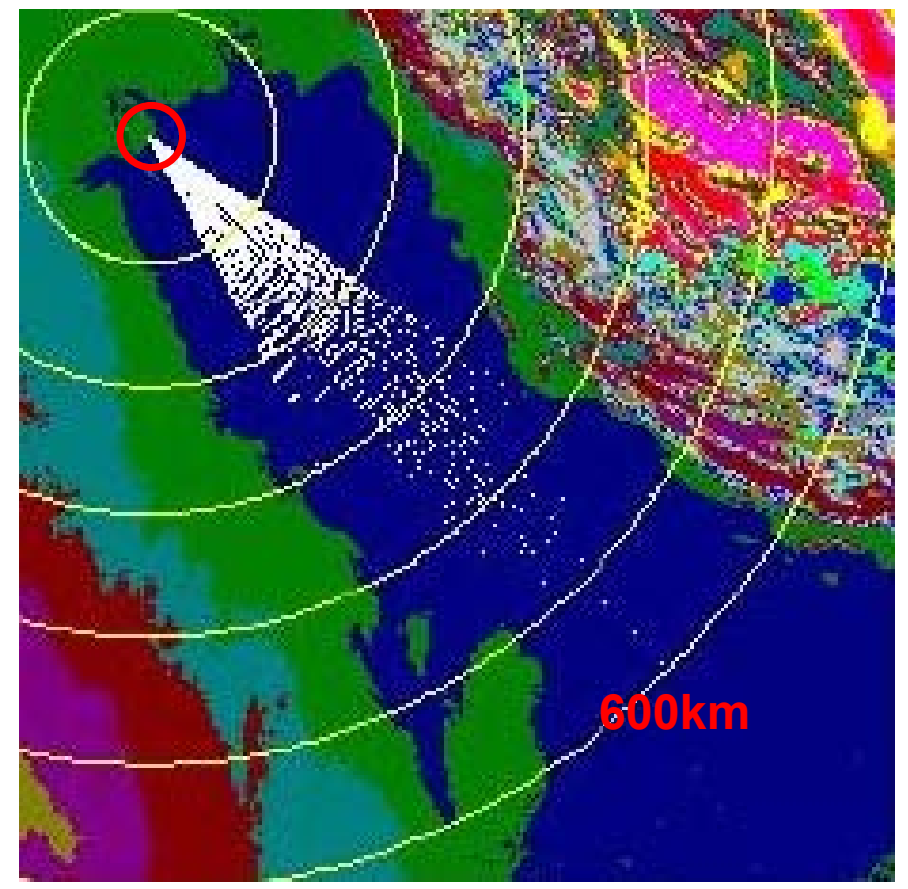

Figure 7. S band detection of a notional target located $10 \mathrm{~m}$ ASL at 1200 UTC on May 14, 2009. White areas in the 123 degree to 153 degree scan indicate ranges where detection occurs. The red ring represents the detection range in a standard atmosphere.

In a standard atmosphere, the detection range is $30 \mathrm{~km}$ indicated by the red ring. The extended detection ranges in this atmosphere are an order of magnitude greater than those in a standard atmosphere. As will be shown in the final paper, similar detection enhancements are observed at $\mathrm{C}$ and $\mathrm{X}$ band.

An $\mathrm{S}$ band analysis of target detection at $100 \mathrm{~m}$ ASL is displayed in figure 8. Detection range in a standard atmosphere is $63 \mathrm{~km}$ as demonstrated by the red circle. Although the detection ranges at $100 \mathrm{~m}$ ASL are enhanced beyond a standard atmosphere, it is more limited than at $10 \mathrm{~m}$ ASL. It can be seen in figure 7 that at $100 \mathrm{~m} \mathrm{ASL}$, there is an extended range of 0 to $-5 \mathrm{~dB}$ propagation factor that diminishes rapidly after $150 \mathrm{~km}$ because of the large amount of energy trapped in the extended SIBL. Similar gains beyond standard atmosphere detection at $100 \mathrm{~m}$ ASL are observed at X band, but not $\mathrm{C}$ band. 


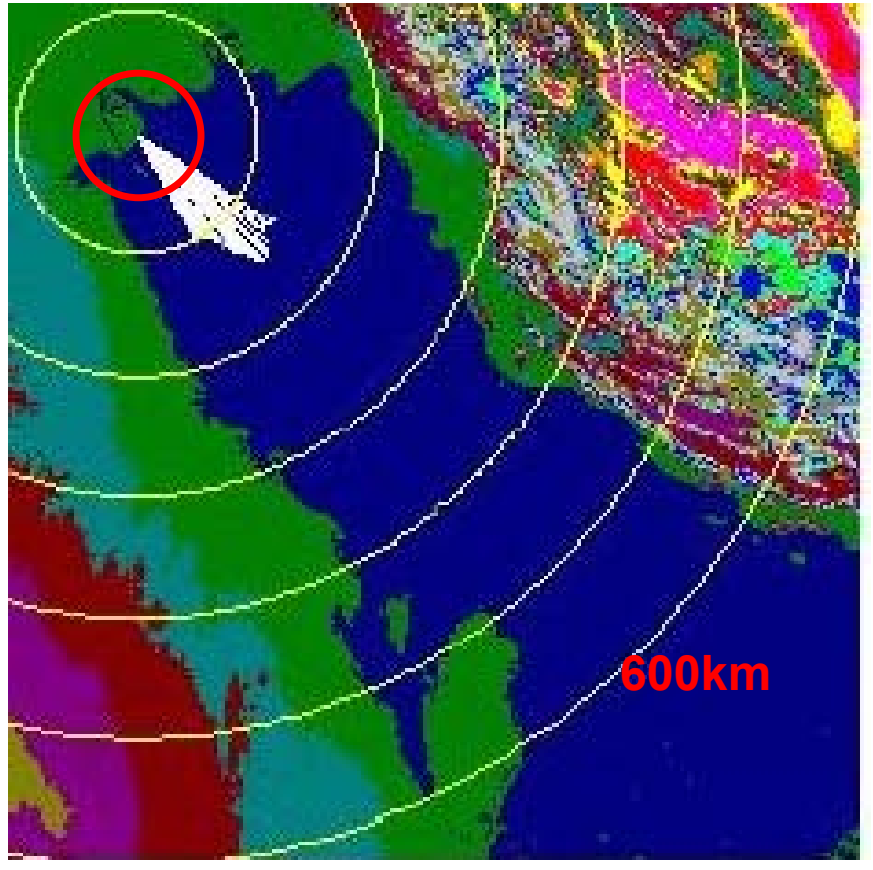

Figure 8 . $\mathrm{S}$ band detection of a notional target located $100 \mathrm{~m}$ ASL at 1200UTC on May 14, 2009. White areas in the 123 degree to 153 degree scan indicate ranges where detection occurs. The red ring represents the detection range in a standard atmosphere.

$\mathrm{C}$ band propagation factor along the dashed red line in figure 1 is plotted in figure 9 .
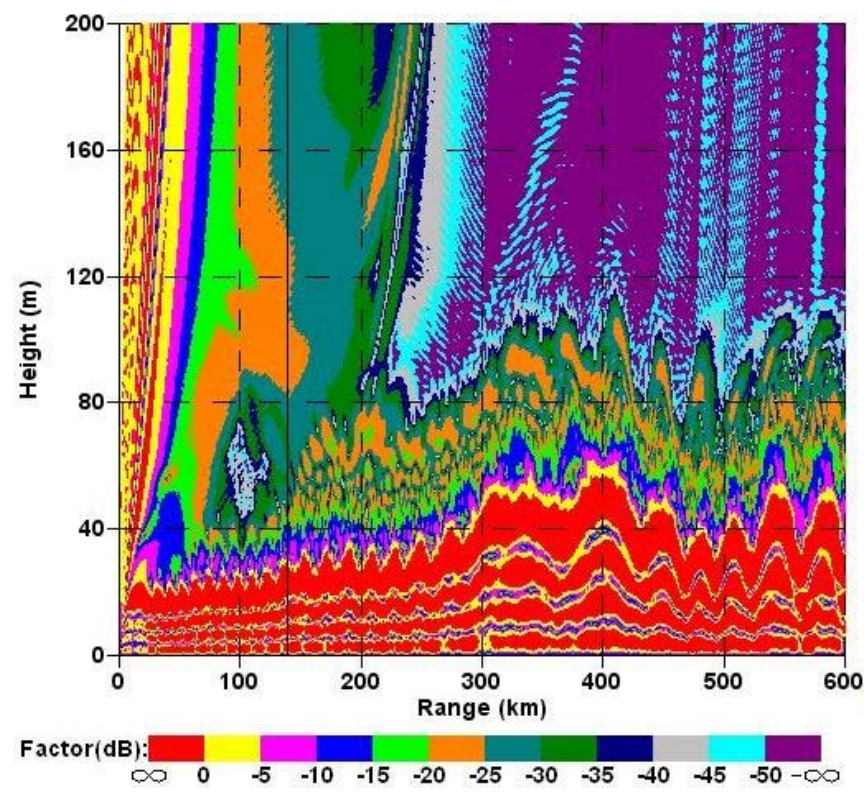

Figure 9. C band propagation factor along the 135 degree azimuth indicated by the dashed red line in figure 1 at 1200UTC on May 14, 2009.

As with $\mathrm{S}$ band, the energy is trapped in a shallow layer extending out to $600 \mathrm{~km}$ from the radar. Propagation factor for the notional $\mathrm{X}$ band radar is displayed in figure 10 and demonstrates similar trapping characteristics.

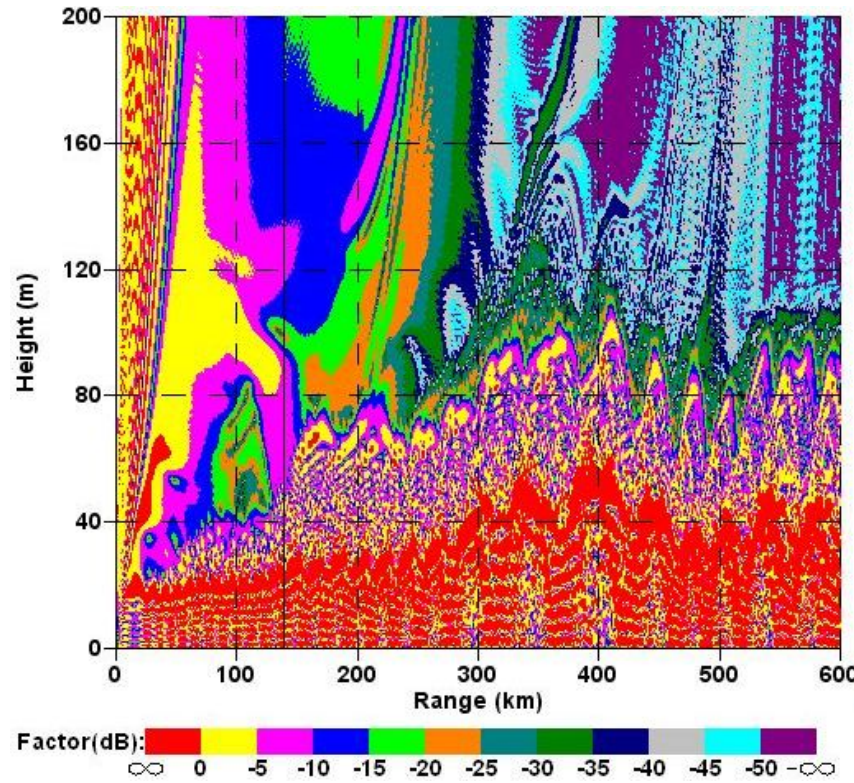

Figure 10. $\mathrm{X}$ band propagation factor along the 135 degree azimuth indicated by the dashed red line in figure 1 at 1200UTC on May 14, 2009.

$\mathrm{C}$ band radar detection of the notional target at $10 \mathrm{~m}$ ASL is delineated in figure 11 .

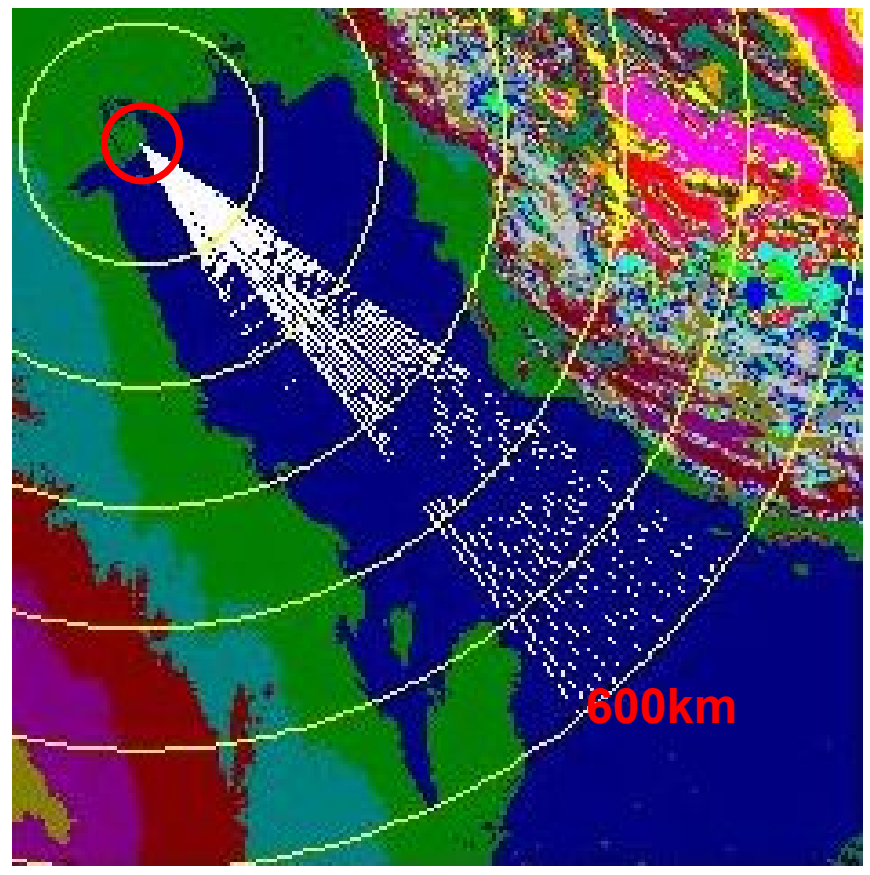

Figure 11. C band detection of a notional target located 10m ASL at 1200UTC on May 14, 2009. White areas in the 123 degree to 153 degree scan indicate ranges where detection occurs. The red ring represents the detection range in a standard atmosphere.

As with $\mathrm{S}$ band, the target detection range at $\mathrm{C}$ band is greatly extended with more detection area in the 500 to $600 \mathrm{~km}$ range. Figure 12 is a similar analysis for the notional $\mathrm{C}$ band radar with the target at $100 \mathrm{~m}$ ASL. 


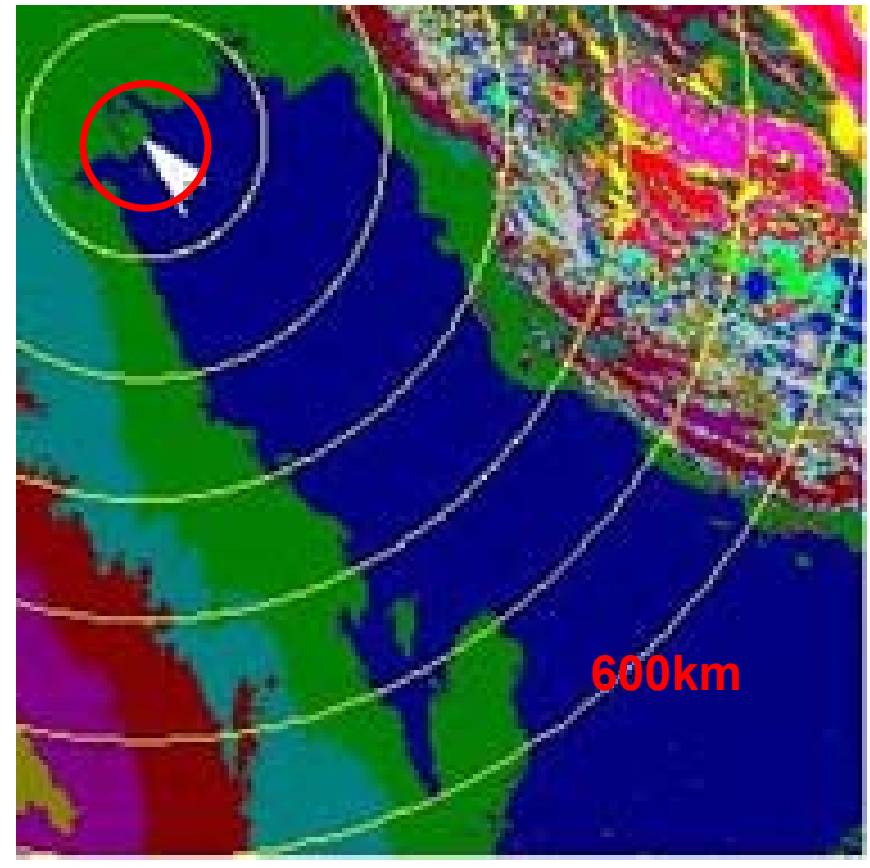

Figure 12. C band detection of a notional target located $100 \mathrm{~m}$ ASL at $1200 \mathrm{UTC}$ on May 14, 2009. White areas in the 123 degree to 153 degree scan indicate ranges where detection occurs. The red ring represents the detection range in a standard atmosphere.

It can be seen in figure 9 that the $\mathrm{C}$ band one way propagation factor between 50 and $100 \mathrm{~km}$ at $100 \mathrm{~m} \mathrm{ASL}$ is at least $20 \mathrm{~dB}$ below that at $\mathrm{S}$ band. The $\mathrm{X}$ band analysis follows in figures 13 and 14

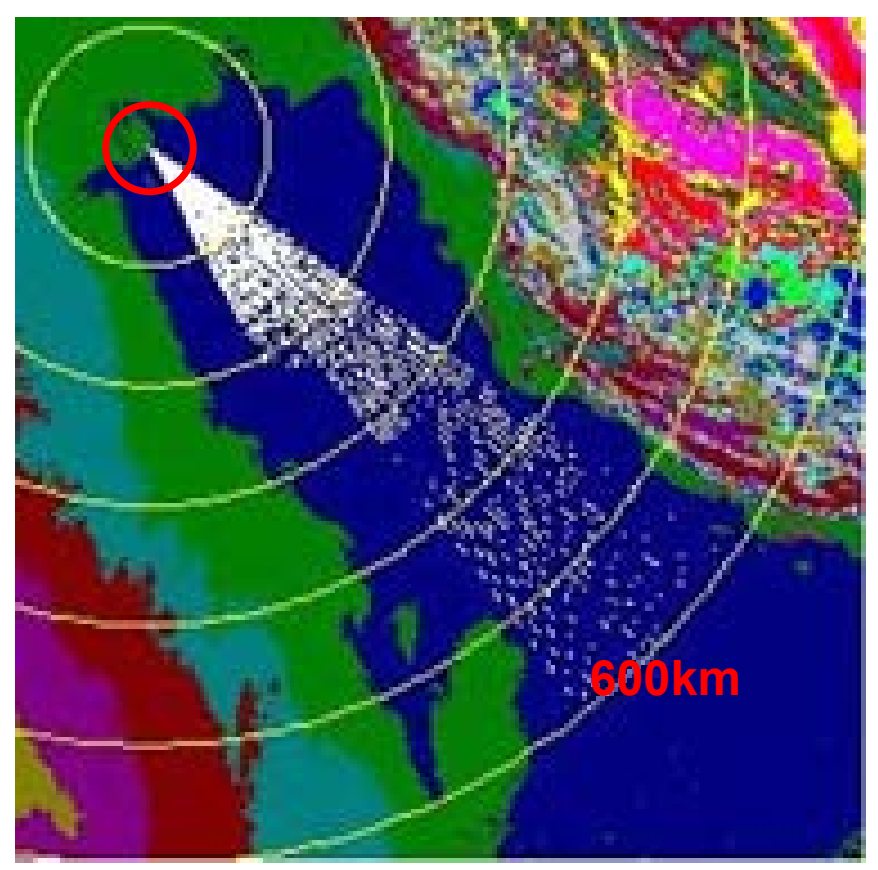

Figure 13. $\mathrm{X}$ band detection of a notional target located 10m ASL at 1200 UTC on May 14, 2009. White areas in the 123 degree to 153 degree scan indicate ranges where detection occurs. The red ring represents the detection range in a standard atmosphere.
Similar to $\mathrm{S}$ and $\mathrm{C}$, the $\mathrm{X}$ band detection of the notional target extends out to $600 \mathrm{~km}$. The $\mathrm{X}$ band detection range at $100 \mathrm{~m}$ ASL, as shown in figure 14 , extends well beyond $100 \mathrm{~km}$. This is due to the 0 to $-5 \mathrm{~dB}$ propagation factor from 30 to $100 \mathrm{~km}$ at $100 \mathrm{~m}$ ASL as shown in figure 10 .

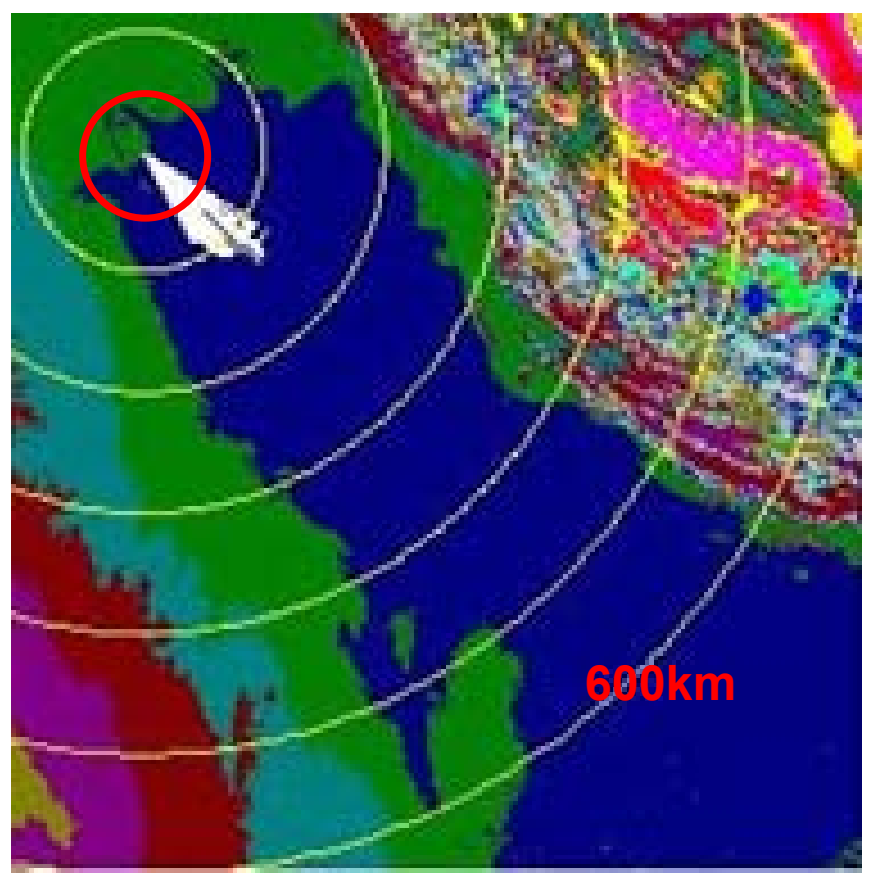

Figure 14. X band detection of a notional target located $100 \mathrm{~m} \mathrm{ASL}$ at 1200UTC on May 14, 2009. White areas in the 123 degree to 153 degree scan indicate ranges where detection occurs. The red ring represents the detection range in a standard atmosphere.

\section{CONCLUSIONS}

Trapping layers can exist for hundreds of kilometers over the water when warm and less humid air flows offshore over colder water. The broad picture of extended detection range below the ducts is similar at $\mathrm{S}, \mathrm{C}$ and $\mathrm{X}$ bands. The details are due to wavelength dependent clutter to noise calculations and distances between trapping layer nulls. Sea surface temperature variations change the thermal stability of the trapping layers leading to a change in trapping layer height Wavelength dependent propagation factor structures immediately above the ducts lead to significant differences in detection range characteristics above the stable internal boundary layers.

\section{REFERENCES}

[1] R. E. Marshall, W. D. Thornton, G. H. Lefurjah and T. S. Casey, Modeling and Simulation of Notional Future Radar in Non-Standard Propagation Environments Facilitated by Mesoscale Numerical Weather Prediction Modeling, accepted for Naval Institute Proceedings, April 2009

[2] A. Smedman, H Bergstrom and B. Grisogono, Evolution of Stable Internal Boundary Layers Over a Cold Sea, Journal of Geophysical Research, Vol. 102, pp1091-1099, January, 1997

[3] R. Hodur, J. Pullen, J. Cummings, X. Dong, J. Doyle, P. Martin and M. 
Rennick, The Couple Ocean Atmosphere Prediction System (COAMPS $\left({ }^{\circledR}\right)$, Oceanography, 15, 88-99, 2002

[4] W. L. Patterson, Advanced Refractive Effects Prediction System Version 3.0 Users Manual, Space and Naval Warfare Systems Center, San Diego, CA, 2006 